\section{8}

9

0

31

\title{
The Adaptive Marine Policy (AMP) Toolbox: supporting policy-makers developing adaptive policies in the Mediterranean and Black Seas
}

(1)

Garmendia, M.(1)*, Sauzade, D.(2), Beaumont, N.(3), Boteler, B.(4), Boudine, T.(2), Breil M.(5), Furlan, E.(6), Kontogianni, A.(7), Krüger, I.(4), Le Tellier, J.(2), Gileva, E.(8), March D.(9), Markandya, A.(1), Ojea, E. (1), Pascual, M. (1), Roeleveld, G.(10), Ronco, P.(11), Shivarov, A.(8), Skourtos, M.(12)

(1) Basque Centre for Climate Change (BC3), Alameda Urquijo 4 , 4aㅡ, 48008 Bilbao, Bizkaia, Spain.

(2) Plan Bleu (PB), Villa Valmer, 271 Corniche Kennedy, 13007 Marseille, France.

(3) Plymouth Marine Laboratory (PML), Prospect Place, Plymouth, PL1 3DH, UK.

(4) Ecologic Institute, Pfalzburger Straße 43/44, 10717 Berlin, Germany.

(5) Centro Euro-Mediterraneo per Cambiamenti Climatici (CMCC), Isola di S.Giorgio, 6, 30124 Venezia, Italy.

(6) Università Ca' Foscari, Dorsoduro 3246 - 30123 Venezia, Italy

(7) University of Western Macedonia (UOWM), Parko Agiou Dimitriou, GR 50100, Greece.

(8) Black Sea NGO Network (BSNN), P.O.Box 91, 2 Dr. L. Zamenhof Str., fl. 2, 9000 Varna, Bulgaria.

(9) IMEDEA, Instituto Mediterraneo de Estudios Avanzados (IMEDEA), Carrer de Miquel Marqués, 21, 07190 Esporles, Illes Balears, Spain.

(10) Deltares, P.O. Box 177, 2600 MH Delft, The Netherlands.

(11) Università Degli Studi di Padova, Via Marzolo, 9 - 35131 Padova, Italy.

(12) Agricultural University of Athens (AUA), lera Odos 75, 11855 Athens, Greece.

*Corresponding author: Tel.: +34 944014690. E-mail: maialen.garmendia@bc3research.org

Keywords: Adaptive management; Adaptive policies; Ecosystem-based approach; Marine Strategy Framework Directive; Mediterranean and Black Seas; Adaptive Marine Policy Toolbox; Marine litter 
35 Adaptive management is essential to the practical application of the Ecosystem-Based Approach (EBA). 36 There are frequent assertions that adaptive (learning-based) management is being used. However, there

37 has been only limited progress in promoting learning-based management and evidence on its success is 38 still limited. Indeed, it is difficult to bring the different elements of adaptive management together in a 39 robust and acceptable way and to choose the appropriate tools to do it. For this reason, it is necessary 40 to provide a practical framework for policy action and to enable action to be adaptive and consistent 41 with the regulations and agreements calling for the EBA. Accordingly, to operationalize the design and 42 implementation of truly adaptive policies on the basis of the EBA, the Adaptive Marine Policy Toolbox 43 (hereafter, AMP Toolbox) has been developed. The overall objective of the toolbox is to provide policy44 makers a practical framework to design and implement adaptive policies and reducing uncertainty 45 through learning-based management. In addition, in order to show the utility of the toolbox, the 46 guidelines and resources provided within the toolbox have been applied to the marine litter issue in the 47 Mediterranean and Black Sea as an example. The example has shown that the toolbox is a useful and 48 operational framework to build a science-policy interface according to the EBA and thus improve marine 49 governance. Some resources provided within the toolbox could be somewhat "insufficient", however, 50 they provide a practical and useful starting point to support the application and compilation of the 51 different steps and key activities. Finally, their update and management will suppose an important 52 challenge, since the resources should be continuously adapted when new knowledge becomes available. 


\section{INTRODUCTION}

55 Marine ecosystems provide multiple services such as provisioning of food, energy and mineral resources, and also the regulation of important functions such as nutrient cycling and climate regulation. However, these ecosystems, and thus the services they provide, are subjected to competing uses such as fishing, food and energy production, waste disposal and marine transport to name a few (Halpern et al. 2008). These impacts of these activities, together with the impacts of climate change, are leading to concurrent shifts in marine ecosystems, with potentially wide-ranging biological (Bertram and Rehdanz 2013) and socioeconomic consequences (Sumaila et al. 2011). There are many uncertainties regarding the consequences of these shifts, which introduce yet more complexity to the management of marine ecosystems and resources, given that marine ecosystems are intrinsically dynamic and complex (i.e. they continuously evolve through non-linear dynamics and functions) (O'Higgins, Cooper, et al. 2014). Accordingly, there is need for an approach that integrates social and ecological concerns in management, accounts for the value of ecosystem services, and adjusts to changing circumstances (Bainbridge et al. 2011). The environmental management approach which incorporates such considerations is known as the Ecosystem-based Approach (EBA) or Ecosystem Approach (EA) (Farmer et al. 2012). These terms are used in the same context and could be, therefore, used inter-changeably (Farmer et al. 2012), but for clarity EBA is used in this instance.

Several regulations such as different regional conventions (i.e. Helsinki, Oslo-Paris, Barcelona and Bucharest Conventions) and the Convention on Biological Diversity (CBD) require application of the EBA in order to manage human activities impacting marine ecosystems. On a European policy level, in 2008 the European Union adopted the Marine Strategy Framework Directive (MSFD) (European Commission 2008). The MSFD establishes a framework for Member States to develop marine strategies and execute the necessary measures (i.e. through a Programme of Measures) to achieve or maintain Good Environmental Status (GES) byr 2020. Marine strategies within the MSFD are required to apply an EBA to the management of human activities, ensuring that the collective pressure of such activities is kept within levels compatible with the achievement of GES and that the capacity of marine ecosystems to respond to human-induced changes is not compromised, while enabling the sustainable use of marine goods and services by present and future generations (European Commission 2008). However, the Directive does not define the concept of EBA and no further elaboration on the EBA is provided (Farmer et al. 2012).

The CBD (Convention on Biological Diversity 2000), in contrast, provides a detailed description of the EBA approach, defining it as "a strategy for the integrated management of land, water and living resources that promotes conservation and sustainable use in an equitable way. It is based on the application of appropriate scientific methodologies focused on levels of biological organization, which encompass the essential structure, processes, functions and interactions among organisms and their environment. It recognizes that humans, with their cultural diversity, are an integral component of many ecosystems" (Convention on Biological Diversity 2000). In addition, the CBD requires adaptive management to deal with the complex and dynamic nature of ecosystems and the absence of complete knowledge or understanding of their functioning. As mentioned above, ecosystem processes are often non-linear, which results in discontinuities, leading to surprise and uncertainty (Convention on Biological 
Diversity 2000). Consequently, management must be adaptive in order to be able to respond to such uncertainties and contain elements of "learning-by-doing" feedback. In fact, adaptive management is seen as an evolving process that includes learning (the accumulation of understanding over time) and adaptation (the adjustment of management over time). The sequential cycle of learning and adaptation targets better understanding of the resource system (i.e. reducing uncertainty), and better management based on that understanding (Williams and Brown 2014). Consequently, measures may need to be taken even when some cause-and effect relationships are not yet fully established scientifically (Convention on Biological Diversity 2000). Hence, the presence of uncertainty and knowledge gaps do not justify policy inaction.

However, although adaptive management is essential to the practical application of the EBA and there are frequent assertions that adaptive (learning-based) management is being used, there has been only limited progress in promoting learning-based management and evidence on its success is still limited. Indeed, it is difficult to bring the different elements of adaptive management together in a robust and acceptable way and to choose the appropriate tools to do it (Farmer et al. 2012; Williams and Brown 2014). For this reason, it is necessary to provide a practical framework for policy action and to enable action to be adaptive as well as consistent with the MSFD and international agreements calling for the EBA. This is particularly important in Southern European Seas (i.e. Mediterranean and Black Sea), where the geopolitical and economic disparity together with overlapped governance instruments or environmental management arrangements hinders a shared action toward achieving environmental goals across them, including the implementation of the MFSD (Cinnirella et al. 2014; O'Higgins, Farmer, et al. 2014).

Accordingly, in order to operationalize the design and implementation of truly adaptive policies on the basis of the EBA, the Adaptive Marine Policy Toolbox (hereafter, AMP Toolbox) has been developed. The toolbox is focused on the needs of policy-makers of both EU and non-EU Member States around the Mediterranean and the Black Sea, but it is not limited to this geographical context. In addition, in order to show the usefulness of the AMP toolbox to design and implement adaptive measures under the MSFD and additional regulations calling for the EBA, the guidelines and resources provided within the toolbox have been applied to the case of the marine litter issue in the Mediterranean and Black Sea.

To sum up, the objective of this paper is to present the AMP Toolbox and to demonstrate its value in developing adaptive policies under the MSFD and other regulations calling for the EBA. For this purpose we: (i) present the core principles and structure of the AMP Toolbox (section 2); (ii) apply the AMP Toolbox to the marine litter issue in the Mediterranean and Black Sea (section 3); and, (iii) provide some concluding remarks (section 4).

\section{THE ADAPTIVE MARINE POLICY TOOLBOX}

\subsection{Objective}

The overall objective of the AMP Toolbox is to provide policy-makers within the Mediterranean and Black Seas the necessary support to develop adaptive policies or measures to achieve or maintain GES under the requirements of the MSFD, as well as different international and regional regulations calling 
for the application of EBA to the management of human activities impacting marine ecosystems. The tool box can be found here at the following web address: http://www.perseusnet.eu/en/about_the_apf_toolbox/index.html

\subsection{Structure}

For any web-based toolbox a clear and recognizable structure is very important, as it helps users to find their way easily through an abundance of information. Following the model of the United Nations Food and Agriculture Organization's Ecosystem Approach to Fisheries Toolbox (hereafter, FAO-EAF Toolbox) (http://www.fao.org/fishery/en), the AMP toolbox has been structured in four levels of information, i.e. main page, steps, key activities, resources and examples (Figure 2). An overview of this structure, including the formats used for each level is given below.

\subsubsection{Level 1-Main page}

In the first level, the structure of the toolbox is shown, which is based on the policy-making cycle suggested by the MSFD (Figure 2). The policy cycle contains five steps: 1-set the scene; 2-assemble a basic policy; 3-make the policy robust; 4-implement the policy; and, 5-evaluate and adjust the policies. The adaptive and flexible policy making cycle is based on principles (and methodologies) used in other policy fields (Holling 2005; Swanson and Bhadwal 2009; Walters 1986; Williams and Brown 2014), which have been adapted to the specific needs of the MSFD. These principles include: (i) engagement of the broader stakeholder community; (ii) definition of the problem and desired objectives; (iii) transfer of cross-disciplinary and integrated scientific knowledge to decision-makers (i.e. learning contributes to management by helping to inform decision-making); (iv) forward-looking analysis to promote the identification of robust policies across different scenarios and as a basis for further learning; (v) monitoring of the effects of the implementation of new policies; (vi) implementation of actions/policies to allow continued environmental management while learning (reducing uncertainty); (vii) the incorporation of lessons learnt from monitoring the management interventions (i.e. management contributes to learning) in order to revise models and/or management actions; and, (viii) iterative repetition of this cycle or part of it, so that management reduces uncertainties and leads to improved management outcomes over time. Accordingly, in order to apply these principles in the policy-making process, different guidelines and resources have been incorporated into the toolbox.

Themeaning and potential application of these principles, is exemplified in Box 1which details a possible adaptive strategy for the management of the turbot in Romania and Bulgaria For a detailed description of the application of the policy-cycle, see the marine litter case study in section 3.

The AMP has been structured in a way that allows for a step-wise, cyclical policy-making approach, as well as an independent use of guidelines and resources involved in specific steps of the cycle. The stepwise or the independent implementation of the cycle step will depend on the nature of the problem studied and the relevance of the steps of the adaptive policy-making process. To this end, the AMP aims to propose a flexible framework that could be implemented in the different stages of the marine policymaking. Each policy-maker will have to adapt the framework according to her/his own need and priorities. This could be the case, for example, when management actions are already in use but are 
ineffective because they do not contemplate future uncertainties or the effectiveness of these management actions is not monitored. In such cases steps 3, 4 and 5 can be directly accessed.

\subsubsection{Level 2-Steps}

All the steps are presented in a uniform format, including some basic information (Figure 1) on the step in question. In addition, and most importantly, the key activities (level 3) necessary to accomplish each step can be accessed. Note that the same activity can be addressed within different steps.

2.2.3. Level 3-Key activities

The key activities represent a series of actions which need to be performed to achieve the 5 steps. . The 12 activities are present in a uniform format as well, including an introduction, key questions, key actions and links to the resources necessary to develop the activity in question (Figure 1).

\subsubsection{Level 4-Resources and Examples}

The resources comprise: (i) the "Knowledge base", including 7 databases (i.e. Research Projects; Marine valuation; Inventory of Measures; Inventory of Foresight exercises; Inventory of Ecosystem Based Assessment Studies; Legal Inventory; and, Institutional Inventory); (ii) different "Tools and methods" (e.g.? ); (iii) the "Regional assessments and models dedicated to the Mediterranean and the Black Seas"; and, (iv) "Further readings". One of the most important objectives of the AMP Toolbox is to make available scientific data, information and models (especially those developed within the PERSEUS project) to users and in doing so support policy-making. Whereas the "Knowledge base" and the "Regional assessments and models dedicated to the Mediterranean and Black Seas" have been developed from the work performed within the PERSEUS project; the "Tools and methods" have been selected from different toolboxes or references already available in the literature or on the web. These include: (i) the MESMA (Monitoring and Evaluation of Spatially Managed Areas) Toolbox (https://publicwiki.deltares.nl/display/MESMA/Home); (ii) the Marine Scotland Toolbox; and, (iii) the FAO-EAF Toolbox. Moreover, some of the tools have been compiled from resources provided by different governmental departments (e.g. Directorate General of Development and Cooperation, EuropeAid), environmental research groups or companies. Note that a given resource can be multifunctional or useful for different purposes, thus it can be linked to different key activities and steps.

\section{INSIGHTS INTO THE AMP TOOLBOX USING MARINE LITTER AS AN EXAMPLE}

In this section, the functioning of the AMP toolbox (including its different steps, key activities and resources) is illustrated, through a practical case on marine litter, selected as being a key issue for the Mediterranean and the Black Sea. In fact, the need for proper waste management in the marine environment is increasingly recognized by the international community; and several agreements and directives such as the MSFD require maintaining properties and quantities of marine litter at levels that do not cause harm to the marine environment. Accordingly, using this important environmental problem as a directorial example, we describe and discuss the guidelines provided within the toolbox; and illustrate the different resources available, using information and data from the literature. In the 
following, we assume that each user of the AMP Toolbox is in charge of developing their own placebased policies to tackle their specific problem. However, this toolbox could also be useful for other societal groups who are not in charge of policy-making, but interested in this process, such as: (i) scientist willing to understand how scientific knowledge can be used in policy-making; (ii) stakeholder who may gain or lose with the policies implementation; or, (iii) citizen interested on how our society is regulated.

\subsection{Step 1-Set the Scene}

The first step in the AMP Toolbox is to acknowledge that there is a problem that causes negative impacts and that this merits further analysis and the development of management strategies. Developing a strategy to manage marine litter requires a good understanding of the source of the problem, its scale and impact. Accordingly it is necessary to "Gather information and determine existing conditions" (http://www.perseus-net.eu/site/content.php?artid=2175). For this purpose, the "DriverPressure-State-Welfare-Response (DPSWR) framework"

(http://www.perseusnet.eu/site/content.php?artid=2181) is proposed within the AMP Toolbox. This tool is a widely-known and potentially useful framework to set the scene (Cooper 2012). This framework is useful to link the effects that socio-economic uses have in the marine ecosystems as well as the effects that the degradation of the marine environment has on human wellbeing.

For example, as observed in Figure 3, land-based sources (including land-based activities and coastal tourism), rather than ocean-based sources, are the main sources of marine litter in the Mediterranean and Black Seas (Galgani et al. 2013; UNEP 2009). After entering the sea, litter is accumulating in the Mediterranean and Black Seas ecosystems. In fact, recordings of floating litter have confirmed the overwhelming presence of plastics in the Mediterranean Sea, accounting for about $83 \%$ of observed marine litter items (Galgani et al. 2013). Other known ecological impacts of marine litter include the alteration, damage and degradation of benthic habitats such as coral reefs and benthic macroinvertebrates (Katsanevakis et al. 2007; Wright et al. 2013) as well as entanglement in and ingestion of marine debris by marine organisms (Galgani et al. 2013; Pham et al. 2014). Apart from the aesthetic problem, this environmental degradation causes significant socio-economic impacts such as, loss of tourism and related revenues and endangerment of human health and safety. In addition, it has important financial implications for the fishing sector (Galgani et al. 2013; Oosterhuis et al. 2014; Pham et al. 2014).

Hotspots of marine litter accumulation not only include the coastline (e.g. highly populated areas, beaches, etc.) or surface waters (Cózar et al. 2015), but also submarine canyons where litter from landbased activities has been shown to accumulate in high densities (Pham et al. 2014). However, as a consequence of the lack of standardization in the sampling and analytical methodologies used and the high cost of sampling in the deep sea, limited standardized surveys have been performed across large areas such as the Mediterranean Sea. Consequently, the understanding of the problem extent is also limited (Pham et al. 2014). In fact, determining key sources of knowledge and finding any knowledge gaps are also an important aim of this step. 
Additionally, in this step, as well as throughout the following steps it is necessary to "Involve experts and stakeholders" (http://www.perseus-net.eu/site/content.php?artid=2167) to make them understand the extent of the problem. This will help to create the political will and support for potential action (Ten Brink et al. 2009). Other authors (Bainbridge et al. 2011), have highlighted the lack of stakeholder engagement in the implementation of the MSFD at all the relevant (and necessary) scales and the importance of engaging public consultation and active partnerships from the beginning of the process (according to the EBA). In the case of marine litter also, a wide engagement would be necessary (i.e. regional, national and local authorities, maritime sector, tourism sector, fisheries and aquaculture, agriculture, industry, and civil society). Accordingly, several methods are proposed such as Rapid Policy Network Mapping (Bainbridge et al. 2011) and Stakeholders Mapping or Analysis (Fletcher et al. 2003) in order to support policy maker at this stage. In Figure 4 the principal sectors that are affected by the problem are presented by means of the "Stakeholders Analysis" (http://www.perseusnet.eu/site/content.php?artid=2195) tool included in the AMP Toolbox. Additional tools to organize stakeholders engagement such as "Stakeholder meetings" net.eu/site/content.php?artid=2183) and "Stakeholder workshops"

(http://www.perseusnet.eu/site/content.php?artid=2189) can be also found in the "Resources" section of the toolbox.

Once the current situation has been defined and the stakeholders engaged, and before the possible solutions are listed, it is helpful to develop a clear set of objectives the policy needs to address, and the particular issues it needs to take into account. Initiatives for new actions will need to build on both an understanding of the problem as well as the benefits of addressing it. Indeed, for an effective delivery of the EBA, apart from the multi-sectoral engagement, the valuation of ecosystem services and the recognition of the tight coupling between human and ecological well-being are necessary (Bainbridge et al. 2011; Tallis et al. 2010). Accordingly, it is important to "Develop a mutual understanding and define principles and goals" (http://www.perseus-net.eu/site/content.php?artid=2187). Within the Honolulu Strategy $^{1}$ (UNEP and NOAA 2011) for example, the following three objectives (and the strategies to accomplish these objectives respectively) have been defined: (i) to reduce the amount and impact of land-based sources of marine debris; (ii) to reduce the amount and impact of sea-based sources of marine debris; and, (iii) to reduce the amount and impact of the accumulated marine debris on shorelines, in benthic habitats, and in pelagic waters.

Overall, the adaptive policies might focus on setting goals and targets at the local level, with a stakeholder-led process propagating from local spatial scales upwards toward a unified regional vision and legal formalization (Bainbridge et al. 2011; Tallis et al. 2010). In fact, cooperation and coordination on a regional seas basis is an asset for a meaningful development and implementation of the EBA (Bainbridge et al. 2011). Accordingly, the use of existing institutional structures such as the regional seas commissions and international organization should be promoted (Bainbridge et al. 2011). Indeed, the process will be more effective and simpler when there is a clear understanding of the distribution of

\footnotetext{
${ }^{1}$ The Honolulu Strategy was created during the Fifth International Marine Debris Conference (5IMDC) co-hosted by the National Oceanic and Atmospheric Administration (NOAA) in cooperation with the United Nations Environmental Programme (UNEP) and other agencies and organizations for a comprehensive and global effort to reduce the impacts of marine debris (https://5imdc.wordpress.com/about/honolulustrategy/).
} 
authority for action and enforcement between institutions (Ten Brink et al. 2009). In the "Institutional inventory" (http://www.perseus-net.eu/en/institutional inventory/index.html) of the toolbox some of the intergovernmental organizations related to the marine litter problem can be found. In Table 1 , as an example, some of the organizations represented in the institutional inventory as well as additional ones are shown. Although, these organizations are necessary to implement consistent and cooperative strategies, it is important to decentralize the authority and responsibility for decision-making to the lowest effective and accountable unit of governance as mentioned above (Swanson and Bhadwal 2009). This can increase the capacity of a policy to perform successfully under uncertain conditions. In fact, those closely connected to the resource system are in a better position to adapt to and shape ecosystem changes and dynamics than remote levels of governance (Bainbridge et al. 2011; Swanson and Bhadwal 2009).

Last but not least, existing legal and administrative obligations such as international agreements, laws and regulations should be identified, with the aim of defining consistent objectives and strategies. A list of examples of legal and administrative instruments managing marine litter can be found in the "Legal inventory" (http://www.perseus-net.eu/en/legal inventory/index.html) of the toolbox. In Table 2, some of the instruments described in the legal inventory as well as in the literature (i.e. Commission on the Protection of the Black Sea Against Pollution 2009) can be consulted. Note that although many of these instruments do not target marine litter directly (since they aim at reducing marine pollution, waste production and dispersal or protecting the marine environment in more general terms), they have an indirect effect on marine litter.

\subsection{Step 2-Assemble the basic policy}

Once the problem has been addressed and the desired objectives defined, it is necessary to identify and analyse different possible options. Accordingly, this step includes two activities: "Identify measures" (http://www.perseus-net.eu/site/content.php?artid=2219) and "Prioritize/assess new measures" (http://www.perseus-net.eu/site/content.php?artid=2223). The former requires that the policy-makers look at the full range of possible solutions and develop a list of options taking into consideration the objectives of the policy and the particular issues it needs to take into account. In adaptive policy-making, variation is an important principle to consider in the selection of measures or instruments, since the diversification of the intervention increases the possibilities of succeeding under unanticipated conditions (Swanson and Bhadwal 2009). Moreover, on occasions, a policy is not feasible given political commitments, potential public resistance or capacity constraints. Accordingly, participation by stakeholders enhances the acceptance of instruments as well as offers ideas of whether they could be successful or not. In other words, the involvement of many groups and sectors will help ensure the solution to marine litter is practical and enforceable (i.e. feasible) (Ten Brink et al. 2009). For example, fees for waste services are useful to cover the costs of collection and disposal of waste and also to incentivize consumers to reduce the amount of waste they produce. This should, however, be performed carefully to avoid perverse incentives to dump waste elsewhere. Accordingly, the policy should not only include individual instruments or measures (e.g. charging for waste services) but also facilities and infrastructures and simplification of procedures for discharging waste) (Ten Brink et al. 
2009). In Table 3 for example, a list of potential actions are proposed based on the "Measure inventory" provided within the AMP Toolbox as well as on the Regional Plan on Marine Litter Management in the Mediterranean (UNEP (DEPI)/MED WG. 379/5 2013).

An important action at this stage is to define a set of criteria against the different alternatives will be compared. This selection of criteria will depend on the international or national conditions/circumstances. Ten Brink et al. (2009), for example, have defined ten criteria that can be useful to analyze potential options in order to manage marine litter. These include the degree to which the measure: addresses important specific objectives; has potential to offer significant environmental benefits; raises useful revenues; is fair and equitable; avoids unacceptable social impacts; is consistent with other important economic objectives; is likely to be cost-effective; leads to efficient pricing; is understandable and credible to stakeholders and the public, and is feasible. Afterwards, Ten Brink et al. (2009) recommend that these criteria be scored by experts from 1 to 5 with the aim of ranking all the options. This analysis represents a simple way to prioritize different policy options, as well as to discuss and define the right set of criteria against the different options will be assessed. In addition, Oosterhuis et al. (2014), assess the cost of implementation, effectiveness and externalities of different economic instruments to control marine litter. Though they stress that the choice of the appropriate measure is case specific, largely depending on: (i) the source of pollution (land-based source, e.g. tourist tax, vs. ocean-based sources, e.g. rewards for fishing vessels that return waste); (ii) the country's institutional characteristics and infrastructure (e.g. to launch a landfill tax, the country should have implemented a proper waste management strategy and a properly functioning waste collection and disposal procedure); (iii) consumer's preferences and habitual behavior (i.e. the effect of a measure can temporarily change the behavior and last only as long as the measure is in place); and, (iv) the economy's overall sectorial composition (Oosterhuis et al. 2014).

Then, several types of assessment methods exist which are useful to assess potential measures. These include, for example, impact assessments, cost-effectiveness analysis, coast-benefit analysis, and multicriteria analysis. Information on these tools can be found within the "Prioritize/assess new measures" key activity. In addition, the "Marine valuation database" (http://www.perseusnet.eu/en/database marine valuation/index.html) of the AMP Toolbox contains studies regarding valuations of different management strategies.

\subsection{Step 3-Make the policy robust}

The policy measures drafted in Step 2 must be assembled into a policy which is robust, as far as possible, against future expected and unexpected conditions. This constitutes probably the most specific and innovative step of the AMP Toolbox policy cycle. For this purpose it is necessary to: (i) identify key factors that could affect policy performance as well as linking them to future scenarios in order to study the way these factors might evolve in the future; and, (ii) develop indicators to help trigger important policy adjustments when needed. Accordingly, "Forward looking analysis: assess policy success and risk factors" (http://www.perseus-net.eu/site/content.php?artid=2235) and "Design and implement a monitoring plan" (http://www.perseus-net.eu/site/content.php?artid=2239), are respectively elementary activities within Step 3. 
To identify the key factors that may affect policy performance it is recommendable to develop a deliberative process with multiple stakeholders and experts involved in the implementation of the policy as well as those who are affected (positively or negatively) by the policy in question. Potential future evolution of the key factors can be projected using a combination of qualitative and quantitative methods. Scenarios are a coherent package of key factors. Coherence is achieved by understanding the higher-level drivers for these key factors and how these drivers influence the various key factors. In Table 4 the potential future evolution of key sectors related to the marine litter is presented for the Mediterranean and Black Seas. Scenarios are then quantified using predictive models. They allow forecasting the potential impacts of the policy under various conditions. Models can be as informal as a verbal description of system dynamics, or as formal as a detailed mathematical expression of change.

Regarding the marine litter case, different authors (e.g. Eriksen et al. 2014; Lebreton et al. 2012) have developed and applied numerical models in order to simulate input, transport and accumulation of floating debris in the ocean (i.e. coupling an ocean circulation model to a Lagrangian particle tracking model). Models represent existing understanding of the system including assumptions and predictions, as well as the basis for learning (i.e. learning is gained by comparing predictions generated by the models and data from monitoring and assessment of actual responses, so that understanding gained can provide knowledge for improving models and future management actions).

Once a set of alternatives have been defined and the criteria have been agreed among the stakeholders (see step 2), it is useful to assess the performance of the different alternatives under the scenarios defined at this step. As mentioned before, different methods exist for this purpose., for example, he MCA can be a useful method to assess the robustness of the different policy alternatives under different scenarios.

Monitoring is also a key component in adaptive policies, providing information to evaluate the status of the ecosystems (i.e. environmental status, under the MSFD) and the performance of the policy, as well as triggering policy adjustments in case targets are not achieved (see Steps 4 and 5). To make monitoring useful, in Step 3, the motivation of the monitoring, choices on the monitoring strategy (i.e. selecting the targets and associated indicators to monitor and how to monitor them), and the practical limits (e.g. staff and funding) should be made a priority.

Environmental targets, which indicate either the desired levels of, or necessary changes to pressures, state and impacts which would ultimately result in the achievement of GES, are of paramount importance to guide progress toward achieving GES. In order to achieve sustainable management compatible with the conservation of marine ecosystems, environmental targets for a good status must be defined (Borja et al. 2012). However, due to the lack of data and knowledge on the amount of marine litter in the different marine compartments and the transport (i.e. meteorological and/or hydromorphological processes) and flux mechanisms (i.e. physical fluxes such as the deposition and degradation rates; and, biological fluxes such as absorption and ingestion rates) among them, it is difficult to assess where an ecosystem is positioned along a trajectory toward recovery (Borja et al. 2012). In these cases directional/trend targets (i.e. continuous improvement in state but where a final end point cannot be identified) can be useful. The advantages of this method is that it is easier to get 
good present data than past data; and, that the method only requires relative assessments of ecological quality status, which makes it largely independent of the concept of reference conditions. The absence of an end-point target can be problematic in this method (Borja et al. 2012). However, as mentioned by Galgani et al. (2013), trend-based targets may remain appropriate until an effective alternative is produced. For example, the targets for marine litter could include a reduction percentage or rate in the: (i) number of plastic/fishing/sanitary items on coastlines; (ii) litter density in areas affected by floating litter; (iii) litter density in on the seabed; (iv) micro-plastics; (v) quantity of ingested marine litter by region-specific species, such as the turtle in the Mediterranean Sea (Galgani et al. 2013).

Acknowledging these constraints, the main mandates (EcAp and MSFD) propose using trend indicators to monitor the achievement of the environmental targets. The MSFD proposes four indicators regarding marine litter (European Commission 2010):

(i) Trends in the amount of litter washed ashore and/or deposited on coastlines, including analysis of its composition, spatial distribution and, where possible, source;

(ii) Trends in the amount of litter in the water column (including floating at the surface) and deposited on the seafloor, including analysis of its composition, spatial distribution and, where possible, source;

(iii) Trends in the amount, distribution and, where possible, composition of micro-particles (in particular microplastics); and

(iv) Trends in the amount and composition of litter ingested by marine animals (e.g. stomach analysis).

In addition, in the Mediterranean Action Plan's Ecosystem Approach, 18 "common indicators" have been defined (UNEP/MAP 2014). Among these indicators the abovementioned four have also been proposed. The only difference is that indicators (ii) and (iii) have been unified into a unique one.

Furthermore, not only should the indicators be standardized and harmonized, but also the methods to monitor them. Galgani et al. (2013) make a summary of different approaches to monitor marine litter in different marine compartments and their positive and negative aspects. For example, the most common method to provide data on marine benthos has been trawling. During the last years with the development of optical methods, the use of underwater imaging technology has increased. Both methods have pro's and con's. The former has the advantage of detecting litter items, which would not be detected with imaging technology. Moreover, items are recovered and thus available for analysis in a laboratory. The latter can provide data in places that are difficult to access and does not damage the environment or remove species from their habitat (Pham et al. 2014). Other key relevant documents regarding monitoring methods include the UNEP's "Operational Guidelines for Comprehensive Beach Litter Assessment" (Cheshire et al. 2009), the UNEP/MAP's "Draft Monitoring and Assessment Methodological Guidance on EO10" (UNEP(DEPI)/MED WG.401/3 2014) and the NOAA's "Recommendations for Monitoring Debris Trends in the Marine Environment" (Lippiatt et al. 2013).

The operational targets should also be defined in relation to the nature of the management action required to achieve GES (e.g. amount of marine debris removed); or to assess progress towards full implementation of a specific measure (e.g. percentage of fishers using alternative/modified fishing gear 
by fishing fleet or area). Within the Honolulu Strategy (UNEP and NOAA 2011), several indicators are proposed to evaluate management strategies and their enforcement, focused on three areas: (i) decreasing land-based sources of marine debris; (ii) awareness (and use) of fishers and specific groups of ocean users regarding proper waste storage and disposal options; (iii) removal of marine debris accumulations.

Finally, monitoring a system does not in itself make a policy adaptive. The value of monitoring in adaptive management is inherited from its contribution to decision making. Monitoring must be used to reduce uncertainty (e.g. comparing predictions produced by the models with data-based estimates) (Williams and Brown 2014). The analysis and assessment of monitoring data result in a better understanding of system processes and the opportunity to improve management based on that understanding (see steps 4 and 5). Without periodic monitoring of the relevant resource attributes, learning about resource responses and subsequent adjustment of management actions is impossible (Williams and Brown 2014).

\subsection{Step 4-Implement the policy}

In order to ensure successful policy implementation, several basic conditions need to be fulfilled or arranged. In fact, implementing a policy does not only consist of preparing the legal text, but also ensuring that those who face changes under the new policy understand and expect the policy, its meaning and the implications of their (non-)compliance with it. Accordingly, "Involve experts and stakeholders" (http://www.perseus-net.eu/site/content.php?artid=2167) and "Draw up an implementation plan" (http://www.perseus-net.eu/site/content.php?artid=2240) are key activities within this step. A dedicated implementation plan should provide instructions that are both sufficiently flexible and specific about the actions to be carried out, including who is responsible for these actions and how they can be carried out. A timeline for implementation of the policy should be also included. A "Gantt chart", as proposed in the AMP Toolbox (http://www.perseusnet.eu/site/content.php?artid=2240), can be a useful means to organize actions along a timeline.

Accordingly, in the present step (see Table 5) a theoretical implementation plan to reduce marine litter at sea (particularly from fishing activities) is presented as an example, following the "Guide on best practices for Fishing for Litter (FfL) in the Mediterranean" (UNEP (DEPI)/MED WG.417/13). Obviously, a successful strategy to reduce marine litter will need to integrate all the sectors that impact the ecosystem (i.e. not only fisheries but also urban development, industry, tourism and recreation to name a few). Moreover, it will be necessary to define an implementation plan based on the nature of the problem and the specific alternatives identified and prioritized to deal with the problem in question (i.e. through steps 2 and 3). Hence, FfL has been selected as an example in this case, since the Regional Plan on Marine Litter Management in the Mediterranean (UNEP (DEPI)/MED WG. 379/5 2013) has defined $\mathrm{FfL}$ as one of the most important and potential strategies to reduce the amounts of marine litter at sea and has developed detailed guidelines to accomplish the objective. In addition, this initiative integrates several aspects of adaptive management (with important environmental and socio-economic benefits), such as the integration of broader stakeholder communities (including the harbour and port authorities, waste managers and local authorities) and awareness rising among these sectors and the general public. 
It also contributes to a clear objective, i.e. to remove marine litter from the sea. Furthermore, implementation of the strategy allows learning about the amount and composition of litter at sea, as well as the effect of removing litter from sea (i.e. reduce uncertainty). Finally, it can contribute to changing practices and culture within the fishing sector. Accordingly, in the following sentences this strategy is employed as an example to illustrate steps 4 and 5 .

$\mathrm{FfL}$ consists of incentives for fishermen to facilitate clean-up of the floating litter and mainly the seabed from marine litter caught incidentally and/or generated by fishing vessels in their regular activities including derelict fishing gears. Accordingly, as mentioned above, it is very important to ensure that those stakeholders (particularly fishermen but also fishing companies, port authorities and waste management authorities and companies) who were involved in the earlier activities are also involved in the implementation, as well as make them understanding their co-responsibility in generating and solving the problem. Moreover, successful implementation also requires that the regulatory and institutional frameworks will be in place, including the capacity to enforce and monitor the new policy. So, it would be necessary to ensure that (UNEP (DEPI)/MED WG.417/13):

- A coordinator or coordination group has been defined, which will be in charge of: (i) contacting with fishermen's associations, ports and harbors' authorities, waste management authorities and companies; (ii) developing of the public relations campaigns; (iii) reporting and evaluating monitoring data.

- The training needs of fishermen and vessel owners to perform these functions and achieve useful outcomes, has been identified and fulfilled.

- Guidelines and bags to collect any marine litter they catch in their nets during fishing operations have been provided to the vessels.

- Suitable disposal facilities in ports and harbors (e.g. permanent and large containers that are emptied on regular basis and made available at the shortest possible distance from fishing boats will facilitate handling of both wastes and bags) have been provided by the port authorities.

- Appropriate waste management system has been implemented to guarantee that waste is segregated and recycled conveniently prioritising the recovery from the port deposit. This system could: be integrated in the harbour existing waste management system; be an independent management system managed by an authorised waste manager that ensures its subsequent separation and recovery; or, consist of a combined system of the two previous options.

- A suitable monitoring strategy or plan has been developed, including indicators of the status of the coastal and marine, as well as the effectiveness of the policy.

Once these conditions have been fulfilled or arranged, the specific actions (i.e. "fish" marine litter at sea, collect marine litter at ports and harbours and manage marine litter for recycling, energy recovery and disposal) as well as the monitoring plan are put into place ("Design and implement a monitoring plan", http://www.perseus-net.eu/site/content.php?artid=2239).

\section{Step 5-Evaluate and adjust policies}

515 This step provides both insights in the policy's outcomes and performance and a basis for its 516 adjustment. A regular review or evaluation, even when the policy seems to perform well, can help 517 address emerging issues and trigger important policy adjustments (Williams and Brown 2014). 
Accordingly this step consists of two key activities: (i) evaluate the on-going policy (http://www.perseusnet.eu/site/content.php?artid=2244); and, (ii) adjust to new uprising issues (http://www.perseusnet.eu/site/content.php?artid=2248).

521 Evaluation involves assessing: (i) how much of the problem has been addressed (i.e. measuring the remaining gap between the current status of the coastal and marine ecosystems and the desired condition or status, through the targets and indicators defined in step 3); and, (ii) whether and to what extent the policy is effective. For example, evaluating the composition (i.e. to identify sources of marine litter) and weight (i.e. to ensure the final waste management) of waste brought ashore or/and the number of vessels that participate in the strategy. In addition, it also can involve an analysis of costeffectiveness, distribution effects (whether certain groups are more affected than others), and competitiveness effects. Well-designed policies should designate competent authorities for policy evaluation. Evaluation should be conducted by a group outside the implementation team to ensure objectivity. For instance, the tasks of recording weight and composition and weight of waste brought ashore might be developed qualified personnel and data might be reported to the coordination team in charge of the policy in order to be evaluated. Concurrently, data on the status of the coastal and marine ecosystems collected from the monitoring network should be also informed to the coordination team.

Moreover, if evaluation has shown that policy outcomes are not what it was expected initially, in this key activity what more needs to be done (i.e. corrective action or adjustments) to achieve the objective is defined. If this is the case, the adjustments required should follow in a simplified way the design and implementation process described in Steps 2, 3 and 4, including specific adjustments to the monitoring programme.

For instance, if the evaluation phase reveals a problem (e.g. trends in the amount of litter deposited on the seafloor do not improve), recommendations should be made by the competent authority to improve the efficiency of the policy (e.g. increase incentives to collect marine litter and return litter to port facilities; and/or, increase sanctions for dumping). As the new adjustments are performed, they should include procedures that allow the policies to be revised without the need to recourse to lengthy legal procedures (Ten Brink et al. 2009). Some capacity to revise the policies can be created within the policy itself (e.g., that the coordination group responsible for the policy, can revise rates every year with broad constraints) and not require new legislation (Ten Brink et al. 2009). In some cases, institutions should be given the rights to fine-tune the policy (e.g., raise or lower levels) without overlong legal requirements (Ten Brink et al. 2009). This can be useful to reduce the risk of political blockage of a needed development of the policy (Ten Brink et al. 2009). However, for more fundamental changes, new policies may be needed and the complete cycle repeated. In addition, in order to learn about the decisionmaking process, the MSFD and EcAp require the repetition of the complete cycle periodically (e.g. 6yearly in the case of the MSFD), reconsidering the different phases of the set-up process such as the setting of the objectives and the identification and selection of management alternatives.

\section{CONCLUSIONS}


With the overall aim of operationalizing the design and implementation of adaptive policies under the requirements of the MSFD, as well as different regulations calling for the EBA, the AMP Toolbox has been developed. In fact, the AMP toolbox should be understood as a practical framework to support policy-makers designing and implementing adaptive policies and reducing uncertainty through learningbased management, according to the EBA.

The AMP has been structured in a way that allows for a step-wise, cyclical policy-making approach, as well as an independent use of guidelines and resources involved in specific steps of the cycle. Certainly, the step-wise or the independent implementation of the cycle step will depend on the nature of the problem studied and the relevance of the steps of the adaptive policy-making process. Indeed, the aim of the AMP toolbox is to propose a flexible framework that could be implemented in different stages of the marine policy-making. Each policy-maker will have to adapt the framework according to her/his own need and priorities.

Additionally, in this case, in order to show the utility of the toolbox, the guidelines and resources provided within the toolbox have been applied to the marine litter issue in the Mediterranean and Black Sea as an example. The example has shown that the toolbox is a useful and operational framework to build a science-policy interface according to the EBA and thus improve marine governance. In fact, technical assistance (i.e. access to information and research) and capacity support will enhance the ability of the policy-makers to design and implement adaptive effective policies and to fully comply with the EBA. Although, some resources could be somewhat incomplete? and will continually evolve "insufficient", they suppose a practical and useful starting point to support the application and compilation of the different steps and key activities. In addition, their update and management will suppose an important challenge, since the resources should be continuously adapted when new knowledge becomes available.

\section{ACKNOWLEDGMENTS}

This work is part of the ongoing research project entitled "Policy-oriented marine Environmental Research for the Southern European Seas" (PERSEUS, http://www.perseus-net.eu/site/content.php;

Grant Agreement No. 287600) within the EU FP7 Theme "Oceans of Tomorrow".




\section{REFERENCES}

Bainbridge, J. M., Potts, T., \& O’Higgins, T. G. (2011). Rapid Policy Network Mapping: A New Method for Understanding Governance Structures for Implementation of Marine Environmental Policy. PLoS ONE, 6(10), e26149. doi:10.1371/journal.pone.0026149

Bertram, C., \& Rehdanz, K. (2013). On the environmental effectiveness of the EU Marine Strategy Framework Directive. Marine Policy, 38, 25-40. doi:10.1016/j.marpol.2012.05.016

Borja, Á., Dauer, D. M., \& Grémare, A. (2012). The importance of setting targets and reference conditions in assessing marine ecosystem quality. Ecological Indicators, 12(1), 1-7. doi:10.1016/j.ecolind.2011.06.018

Cheshire, A. C., Adler, E., Barbière, J., Cohen, Y., Evans, S., Jarayabhand, S., et al. (2009). UNEP/IOC Guidelines on Survey and Monitoring of Marine Litter. (No. 186) (p. 120). United Nations Environment Programme and Intergovernmental Oceanographic Commission. http://www.unep.org/regionalseas/marinelitter/publications/

Cinnirella, S., Sardà, R., Suárez de Vivero, J. L., Brennan, R., Barausse, A., Icely, J., et al. (2014). Steps toward a shared governance response for achieving Good Environmental Status in the Mediterranean Sea. Ecology and Society, 19(4). doi:10.5751/ES-07065-190447

Commission on the Protection of the Black Sea Against Pollution. (2009). Marine Litter in the Black Sea Region. http://www.blacksea-commission.org/_publ-ML.asp

Convention on Biological Diversity. (2000). Conference of the Parties. COP 5 Decision V/6. Convention on Biological Diversity.

Cooper, L. (2012). The DPSWR Social-Ecological Accounting Framework: Notes on its Definition and Application. Policy Brief No. 3. EU FP7 KNOWSEAS Project. http://www.knowseas.com/linksand-data/policy-briefs/DPSWR_Policy\%20Brief-FINAL.pdf/view 
605 606 607 608 609 610 611 612 613 614 615 616 617 618 619 620 621 622 623 624 625 626 627 628

Cózar, A., Sanz-Martín, M., Martí, E., González-Gordillo, J. I., Ubeda, B., Gálvez, J. Á., et al. (2015). Plastic Accumulation in the Mediterranean Sea. PLOS ONE, 10(4), e0121762. doi:10.1371/journal.pone.0121762

Eriksen, M., Lebreton, L. C. M., Carson, H. S., Thiel, M., Moore, C. J., Borerro, J. C., et al. (2014). Plastic Pollution in the World's Oceans: More than 5 Trillion Plastic Pieces Weighing over 250,000 Tons Afloat at Sea. PLoS ONE, 9(12), e111913. doi:10.1371/journal.pone.0111913

European Commission. Directive 2008/56/EC of the European Parliament and of the Council establishing a framework for community action in the field of marine environmental policy (Marine Strategy Framework Directive) (2008). http://eur-lex.europa.eu/legalcontent/EN/TXT/?uri=CELEX:32008L0056

European Commission. Comission Decision on criteria and methodological standards on good environmental status of marine waters (2010). http://eurlex.europa.eu/LexUriServ/LexUriServ.do?uri=OJ:L:2010:232:0014:0024:EN:PDF

Farmer, A., Mee, L., Langmead, O., Cooper, P., Kannen, A., Kershaw, P., \& Cherrier, V. (2012). The Ecosystem Approach in Marine Management. EU FP7 KNOWSEAS Project.

Fletcher, A., Guthrie, J., Steane, P., Roos, G., \& Pike, S. (2003). Mapping stakeholder perceptions for a third sector organization. Journal of Intellectual Capital, 4(4), 505-527. doi:10.1108/14691930310504536

Galgani, F., Hanke, G., Werner, S., \& Vrees, L. D. (2013). Marine litter within the European Marine Strategy Framework Directive. ICES Journal of Marine Science: Journal du Conseil, 70(6), 10551064. doi:10.1093/icesjms/fst122

Halpern, B. S., Walbridge, S., Selkoe, K. A., Kappel, C. V., Micheli, F., D’Agrosa, C., et al. (2008). A Global Map of Human Impact on Marine Ecosystems. Science, 319(5865), 948-952. doi:10.1126/science.1149345 
Holling, C. S. (2005). Adaptive Environmental Assessment and Management. Caldwell, NJ: The Blackburn Press.

Katsanevakis, S., Verriopoulos, G., Nicolaidou, A., \& Thessalou-Legaki, M. (2007). Effect of marine litter on the benthic megafauna of coastal soft bottoms: A manipulative field experiment. Marine Pollution Bulletin, 54(6), 771-778. doi:10.1016/j.marpolbul.2006.12.016

Lebreton, L. C.-M., Greer, S. D., \& Borrero, J. C. (2012). Numerical modelling of floating debris in the world's oceans. Marine Pollution Bulletin, 64(3), 653-661. doi:10.1016/j.marpolbul.2011.10.027

Lippiatt, S., Opfer, S., \& Arthur, C. (2013). Marine Debris Monitoring and Assessment: Recommendations for Monitoring Debris Trends in the Marine Environment. NOAA Technical Memorandum NOSOR\&R-46.

O’Higgins, T., Cooper, P., Roth, E., Newton, A., Farmer, A., Goulding, I. C., \& Tett, P. (2014). Temporal constraints on ecosystem management: definitions and examples from Europe\&amp;\#8217;s regional seas. Ecology and Society, 19(4). doi:10.5751/ES-06507-190446

O’Higgins, T., Farmer, A., Daskalov, G., Knudsen, S., \& Mee, L. (2014). Achieving good environmental status in the Black Sea: scale mismatches in environmental management. Ecology and Society, 19(3). doi:10.5751/ES-06707-190354

Oosterhuis, F., Papyrakis, E., \& Boteler, B. (2014). Economic instruments and marine litter control. Ocean \& Coastal Management, 102, Part A, 47-54. doi:10.1016/j.ocecoaman.2014.08.005

Pham, C. K., Ramirez-Llodra, E., Alt, C. H. S., Amaro, T., Bergmann, M., Canals, M., et al. (2014). Marine Litter Distribution and Density in European Seas, from the Shelves to Deep Basins. PLoS ONE, 9(4), e95839. doi:10.1371/journal.pone.0095839

Ruckelshaus, M., Klinger, T., Knowlton, N., \& Demaster, D. P. (2008). Marine Ecosystem-based Management in Practice: Scientific and Governance Challenges. BioScience, 1, 53-63. doi:10.1641/B580110 
Sumaila, U. R., Cheung, W. W. L., Lam, V. W. Y., Pauly, D., \& Herrick, S. (2011). Climate change impacts on the biophysics and economics of world fisheries. Nature Climate Change, 1, 449-456. doi:doi:10.1038/nclimate1301

Swanson, D. A., \& Bhadwal, S. (2009). Creating Adaptive Policies: A Guide for Policy-making in an Uncertain World. Sage, IDRC. http://idl-bnc.idrc.ca/dspace/bitstream/10625/40245/1/IDL40245.pdf

Tallis, H., Levin, P. S., Ruckelshaus, M., Lester, S. E., McLeod, K. L., Fluharty, D. L., \& Halpern, B. S. (2010). The many faces of ecosystem-based management: Making the process work today in real places. Marine Policy, 34(2), 340-348. doi:10.1016/j.marpol.2009.08.003

Ten Brink, P., Lutchman, I., Bassi, S., Speck, S., Sheavly, S., Register, K., \& Woolaway, C. (2009). Guidelines on the Use of Market-based Instruments to Address the Problem of Marine Litter ( $\mathrm{p}$. 60). Brussels, Belgium and Virginia Beach, Virginia, USA: Institute for European Environmental Policy (IEEP) and Sheavly Consultants. http://www.unep.org/regionalseas/marinelitter/publications/

UNEP. (2009). Marine Litter: A Global Challenge (p. 232). Nairobi, Kenya: United Nations Environment Programme (UNEP). http://www.unep.org/regionalseas/marinelitter/publications/

UNEP. (2011). Taking Steps toward Marine and Coastal Ecosystem-Based Management. An Introductory Guide.

UNEP (DEPI)/MED WG. 379/5. (2013). Regional Plan for the Marine Litter Management in the Mediterranean. https://www.cbd.int/doc/meetings/mar/mcbem-2014-03/other/mcbem-201403-120-en.pdf

UNEP(DEPI)/MED WG.401/3. (2014). Draft Monitoring and Assessment Methodological Guidance. Athens, Greece: UNEP/MAP. 
676 UNEP/MAP. (2014). UNEP(DEPI)/MED WG. 390/4. Report of the Integrated Correspondence Groups of 677 GES and Targets Meeting. Athens, Greece.

678 UNEP, \& NOAA. (2011). Honolulu Strategy - A Global Farmework for Prevention and Management of 679 Marine Debris (p. 57). Honolulu, Hawái, USA: UNEP and NOAA.

680 http://marinedebris.noaa.gov/solutions/honolulu-strategy

681 Walters, C. J. (1986). Adaptive Management of Renewable Resources. Blackburn Press.

682 Williams, B. K., \& Brown, E. D. (2014). Adaptive Management: From More Talk to Real Action. Environmental Management, 53(2), 465-479. doi:10.1007/s00267-013-0205-7

684 Wright, S. L., Thompson, R. C., \& Galloway, T. S. (2013). The physical impacts of microplastics on marine 685 organisms: A review. Environmental Pollution, 178, 483-492. doi:10.1016/j.envpol.2013.02.031 686 